\title{
APPENDIX III. HYDROCARBON GASES FROM CANNED CORE SAMPLES SITES 174A, 176 AND 180
}

\author{
Richard D. McIver, Esso Production Research Company
}

\section{INTRODUCTION}

From the beginning, gas has been noticed in many of the cores taken in the Deep Sea Drilling Project. Gas is readily detected escaping when the liner is removed from the core barrel and often continues to escape for an hour or two. Frequently gas expansion is strong enough to extrude the sediments from the liner, and it often creates large expansion gaps (up to $10 \mathrm{~cm}$ ) in the cores. These are particularly noticeable in the whole cores from the Cariaco Trench, frozen in the liners to preserve them for organic geochemical investigations. Of course this gas has been a matter of concern to DSDP scientists, but until now only very rough estimates of the amounts of gas have been made, in the form of observations such as very gassy, etc. Some qualitative work (Lancelot and Ewing, 1972) has shown the gas to be predominantly methane with but traces of heavier hydrocarbons (ethane, propane, butanes).

Another related phenomenon, the presence of methane hydrates in sediments sampled on Leg 11, has also been recognized (Lancelot and Ewing, 1972). Certainly the conditions which exist under the deep oceans are conducive to the formation of hydrates of methane if the hydrocarbon is formed in appreciable amounts (Katz, 1971).

In 1971, the Advisory Panel on Organic Geochemistry recommended that small samples of selected cores be sealed in metal cans, as soon as possible after their recovery, to permit more quantitative estimates of the quantities of gas. Although they recognized that some, perhaps much, of the gas contained by the sediment in situ would be lost during the trip to the surface and in handling, they still felt that analyses of the canned specimens might reveal the order of magnitude of hydrocarbon gas in the sediments. They might also reveal significant trends with depth or contrasts from area to area.

Canning of selected samples was begun on Leg 18. Some of the cans were shipped to Esso Production Research Company for analyses. When they arrived, the cans were punctured through a rubber septum clamped to the side. A measured volume of each can's gas space was removed with a hypodermic syringe and introduced into the inlet system of a Perkin-Elmer Model 154B gas chromatograph with a hydrogen-flame ionization detector. The column is a 1-meter P.E. column B (di-2-ethylhexylsebacate); temperature, $46^{\circ} \mathrm{C}$; helium pressure 8 psig; $\mathrm{H}_{2}$ pressure, 8 psig. From the volumes of gas in the cans, the volumes of the sediment, and the gas chromatographic results, the results were calculated as ppm of gas by volume, i.e., cc's of gas at STP per million cc's of sediment as received.

After the analysis, a sample of the sediment was taken and agitated further in a Waring Blender to remove any remaining gases, but the additional quantities removed were so small (a few ppm) that only the cans' gas-volume gases were considered in the analyses. Another sample of some of these sediments was taken for determination of organic carbon, the procedures for which were published previously (Gehman, 1962).

\section{RESULTS}

The results are shown in Table 1 which identifies each sample and gives its organic carbon content (if determined), hydrocarbon gas content in ppm by volume, and the percent of that hydrocarbon gas which was methane.

The organic carbon contents range from 0.16 to 0.70 and are not unusual for deep-sea or shelf-deposited cores analyzed as part of the DSDP program and published in previous Initial Reports of the Deep Sea Drilling Project (Volumes VI-XII). They average less than 0.35 per cent. Therefore, in general the sediments do not appear to be potential petroleum source rocks as defined by Philippi (1957).

The gas contents are erratic, particularly in Holes 174A and 180 . There seem to be no trends with depth, nor any correlation with the organic carbon contents. Of course, not much significance can be attached to the variations; they simply reflect the amount remaining in the sediment when the can was sealed. A coarse-grained (i.e., permeable and porous) sediment would release its gas much more rapidly than a fine-grained one. Therefore, the higher values are probably more indicative of the overall gas contents of the sediment column-and, considering the losses in handling, even the highest values $(41,400 ; 76,000$; and $55,700 \mathrm{ppm}$ ) must be considered minimal.

The more narrow and uniformly higher range of values at Site 176 are puzzling. It may be due to more uniform and finer grain size of the sediments. Still the ranges of values of the other two sites overlap these values.

In the last column, it appears that some of the hydrocarbon gases may be as much as 5.5 percent ethane and higher homologs, but the lower values are associated with the lower total hydrocarbon gas contents. In these cases, the trace of ethane which occurs in virtually every sample sometimes appears to be a significant percentage of the gas even though it is only slightly higher than the background level. Probably not one of the values below 99.0 per cent is significantly different from those above. So, for all intents and purposes, we can consider these gases to be virtually all methane.

This predominance of methane in the hydrocarbon gases suggests that the gas is produced microbially in the near-bottom sediments. Presley and Kaplan (Robert Presely, private communication) performed some carbon 
TABLE I

Results

\begin{tabular}{|c|c|c|c|c|c|c|}
\hline Site & Core & Section & $\begin{array}{l}\text { Depth } \\
\text { in Section } \\
(\mathrm{cm})\end{array}$ & $\begin{array}{l}\text { Percent } \\
\text { Organic } \\
\text { Carbon }\end{array}$ & $\begin{array}{l}\text { PPM (By Volume) } \\
\text { Hydrocarbon } \\
\text { Gas }\end{array}$ & $\begin{array}{l}\text { Percent } \\
\text { Methane } \\
\text { in HC Gas }\end{array}$ \\
\hline $174 \mathrm{~A}$ & 6 & 3 & bottom & 0.21 & 20,700 & 100.0 \\
\hline $174 \mathrm{~A}$ & 6 & 4 & bottom & 0.35 & 13,200 & 100.0 \\
\hline $174 \mathrm{~A}$ & 11 & 5 & bottom & 0.70 & 28,900 & 100.0 \\
\hline $174 \mathrm{~A}$ & 11 & 6 & top & 0.60 & 24,200 & 99.5 \\
\hline $174 \mathrm{~A}$ & 13 & 2 & - & N/A & 300 & $98.7 \mathrm{~b}$ \\
\hline $174 \mathrm{~A}$ & 15 & 4 & top & 0.37 & 24,500 & 99.5 \\
\hline $174 \mathrm{~A}$ & $15^{\mathrm{a}}$ & $4^{a}$ & top & 0.34 & 400 & 99.5 \\
\hline $174 \mathrm{~A}$ & 19 & 4 & bottom & 0.23 & 36,600 & 100.0 \\
\hline $174 \mathrm{~A}$ & 29 & 3 & - & N/A & 22,900 & 99.8 \\
\hline $174 \mathrm{~A}$ & 34 & 3 & bottom & 0.36 & 15,100 & 100.0 \\
\hline $174 \mathrm{~A}$ & $34^{\mathrm{a}}$ & 3 & bottom & 0.32 & 700 & 99.7 \\
\hline $174 \mathrm{~A}$ & 37 & 4 & - & N/A & 1,100 & $98.7^{\mathrm{b}}$ \\
\hline $174 \mathrm{~A}$ & 40 & 5 & top & 0.21 & 500 & $94.5^{\mathrm{b}}$ \\
\hline $174 \mathrm{~A}$ & 40 & 5 & top & 0.16 & 41,400 & 99.5 \\
\hline 176 & 3 & 2 & $144-150$ & 0.30 & 48,000 & 100.0 \\
\hline 176 & $3^{a}$ & $2^{\mathrm{a}}$ & $144-150$ & 0.38 & 76,000 & 100.0 \\
\hline 176 & 4 & 5 & - & $\mathrm{N} / \mathrm{A}$ & 71,100 & 100.0 \\
\hline 176 & 4 & 6 & $146-150$ & 0.17 & 33,200 & 100.0 \\
\hline 176 & 5 & 6 & $142-150$ & 0.35 & 36,600 & 100.0 \\
\hline 176 & $5^{a}$ & $6^{a}$ & $142-150$ & 0.37 & 40,900 & 100.0 \\
\hline 180 & 12 & 2 & $0-5$ & 0.16 & 2,100 & $98.7^{\mathrm{b}}$ \\
\hline 180 & $12^{\mathrm{a}}$ & $2^{\mathrm{a}}$ & $0-5$ & 0.18 & 1,700 & $98.3^{b}$ \\
\hline 180 & 15 & 3 & - & N/A & 600 & $96.5^{b}$ \\
\hline 180 & 18 & 1 & $0-8$ & 0.30 & 1,400 & 99.8 \\
\hline 180 & $18^{\mathrm{a}}$ & $1^{a}$ & & 0.24 & 11,600 & 100.0 \\
\hline 180 & 18 & 4 & - & N/A & 42,800 & 100.0 \\
\hline 180 & 20 & 5 & - & N/A & 55,700 & 100.0 \\
\hline 180 & 24 & 3 & $145-150$ & 0.43 & 1,500 & 99.9 \\
\hline 180 & $24^{a}$ & $3^{a}$ & $145-150$ & 0.43 & 200 & 99.5 \\
\hline
\end{tabular}

${ }^{\mathrm{a}}$ Apparent duplicate of sample immediately above but received in a separate can.

$\mathrm{b}_{\mathrm{Because}}$ of low values of total gas, traces of ethane lower this percentage. However, these values are not significantly different than 100.0 percent.

isotope analyses on gases from the sediments from the same sites, and found the methane to have carbon isotope ratios of about -80 per cent versus PDB. This seems to confirm the microbial origin of the methane, but further work needs to be done in this area.

\section{CONCLUSION}

Although little can be said about the distribution and range of values of hydrocarbon gases in all deep-sea sediments based on this work alone, the amounts in Leg 18 cores are significant, and the data presented herein serve as values against which later samples can be compared. Undoubtedly hydrocarbon gas is a common, if not virtually ubiquitous, constituent of sediments under the oceans; it will be interesting to see what future samples contain.

\section{ACKNOWLEDGMENTS}

The author is indebted to Harvey M. Fry, Shirley Tillotson, and Victoria Rodriquez, who performed the analyses on which this report is based; and to Esso Production Research Company for its continuing support for this work on DSDP samples.

\section{REFERENCES}

Gehman, H. M. Jr., 1962. Organic matter in limestones. Geochim. Cosmochim. Acta. 26, 885 .

Katz, D. L., 1971. Depths to which frozen gas fields (gas hydrates) may be expected. J. Petr. Tech. 23, 419.

Lancelot, Y. and Ewing, J. I., 1972. Correlation of natural gas zonation and carbonate diagenesis in Tertiary Sediments from the northwest Atlantic. In Hollister, C. B., and Ewing, J. I. et al., 1972. Initial Reports of the Deep Sea Drilling Project, Volume XI. Washington (U. S. Government Printing Office). 791.

Philippi, G. T., 1956. Identification of oil source beds by chemical means. Intern. Geol. Congr. 29th, Mexico, 1956. Rept. 25. 